\title{
Relationship between Dopamine and Serotonin on the Effect of Ginkgo biloba Extract in the Treatment of Obsessive-compulsive Disorder in Rodents
}

\author{
J. CHIMAKURTHY*, T. E. G. K. MURTHY1 AND P. V. DIWAN ${ }^{2}$
}

Department of Pharmaceutical Sciences, Vignan's Foundation for Science, Technology \& Research University, Vadlamudi, Guntur-522 213, 'Department of Pharmaceutics, Bapatla College of Pharmacy, Bapatla, Guntur-522 101, ${ }^{2}$ Central Drug Research Laboratory, NGH Institute of Dental Sciences \& Research Centre, Belgaum-590 010, India

Chimakurthy et al.: Ginkgo biloba's standardized extract in the Treatment of Obsessive-compulsive Disorder

In this study, the effect of EGb-761, the standardized extract of Ginkgo biloba at dose levels of 50, 100 and $200 \mathrm{mg} / \mathrm{kg}$ was investigated on experimental models of obsessive-compulsive disorder such as quinpiroleinduced compulsive checking in rats and marble burying behaviour in mice. Water maze test was used to evaluate the effect on spatial memory and the underlying mechanisms were predicted based on rat brain dopamine and serotonin levels. EGb-761 at 100 and $200 \mathrm{mg} / \mathrm{kg}$ showed significant improvement against quinpirole-induced compulsions. A protective effect on memory task was observed in EGb-761-treated rats. This could be attributed to the increase in serotonin and decrease in the dopamine levels. The protective effect of EGb-761 in the treatment of obsessive-compulsive disorder is apparent through the performance in the open field and marble burying behaviour.

Key words: Obsessive-compulsive disorder, Ginkgo biloba, EGb-761, quinpirole, memory, serotonin, dopamine

Obsessive-compulsive disorder (OCD) is a diagnostic and statistical manual of mental disorders-5 and is one of the most common forms of psychological disorder with about $2 \%$ of the population suffering from it at any point of life, all over the world ${ }^{[1]}$. OCD, is a disorder of obsessions that generates recurrent and persistent unwanted thoughts, images or impulses leading to develop compulsions, it can also be defined as a chronic illness causing disability with symptoms that vary in intensity and impair quality of life (QOL), various factors associated with poor QOL such as; comorbid depression, obsessions, low social support, adverse effects of concomitantly used medications such as mood stabilizers and feeling of low social status ${ }^{[2,3]}$ are further making it more debilitating.

The primary loci of these pathological changes are the regions that communicate with basal ganglia and are involved in error detection of brain circuits i.e. hippocampus, globus pallidus, orbitofrontal cortex (OFC), anterior cingulate cortex (ACC), right premotor cortex, left superior temporal gyrus and left dorsolateral prefrontal cortex ${ }^{[4,5]}$. Various theories explaining the neurobiology of $\mathrm{OCD}$, reinstate that repeated stimulation of ACC and OFC result in messages that are excessive and erroneous to the basal ganglia ${ }^{[6]}$, this also leads to comorbidities such as attention deficit hyperactivity disorder and bipolar disorder, general memory deficit ${ }^{[7]}$ and reduced memory confidence ${ }^{[8]}$. Many neurotransmitters play a key role in the aetiology of OCD, of which serotonin's involvement ${ }^{[9,10]}$ is of great importance.

Many medicinal plants such as Rhodiola rosea, Scutellaria lateriflora, Matricaria recutita, Ginkgo biloba, Piper methysticum and Crocus sativus were reported to possess adequate beneficial effect in the treatment of various anxiety disorders and are reported to act through multitude of mechanisms such as altering the neurotransmitter reuptake,

This is an open access article distributed under the terms of the Creative Commons Attribution-NonCommercial-ShareAlike 3.0 License, which allows others to remix, tweak, and build upon the work non-commercially, as long as the author is credited and the new creations are licensed under the identical terms

Accepted 16 March 2019

Revised 22 November 2018

Received 24 August 2018

Indian J Pharm Sci 2019;81(3):431-437 
receptor binding and modulation of endocrine and psychoneuroimmunology ${ }^{[11]}$. EGb-761 (EGb), a standardized extract of the Ginkgo biloba leaf containing $24 \%$ of flavone glycosides (quercetin, kaempferol and iso rhamnetin) and $6 \%$ of terpenes (gingkolides and bilobalides) ${ }^{[12]}$, was chosen to study the effect on OCD, because of the reported efficacy of Ginkgo biloba in the treatment of anxiety ${ }^{[13]}$. The involvement of serotonin, dopamine and noradrenaline in the aetiology of OCD and Gingko biloba's ability to alter the neurotransmitter levels has made us to evaluate the effect of EGb on OCD using two animal models, compulsive-checking induced with quinpirole in rats and marble burying behaviour in mice ${ }^{[14]}$. The effect of EGb on memory was explored using the Morris water maze apparatus ${ }^{[15]}$ and the rat brain monoamine levels were explored to elucidate the extent of efficacy on OCD and predict the relationship between dopamine and serotonin in its treatment.

\section{MATERIALS AND METHODS}

Experiments were performed on Wistar rats (180$200 \mathrm{~g}, 8-10 \mathrm{w})$ and Swiss albino mice (25-30 g, 10-12 w) of either sex, which were procured and housed in accordance to the guidelines of Committee for the Purpose of Control and Supervision of Experiments on Animals (CPCSEA) for experiments on animals. Animals were procured from Mahaveer Enterprises, India, (1656/PO/Bt/S/12/CPCSEA) and the experimental protocols were approved by the Institutional Animal Ethics Committee (IAEC) of Bapatla College of Pharmacy, India (IAEC/VIII/ $\mathrm{BCOP} / 4 / 2016-17)$. The animals were maintained at controlled climatic conditions, $22 \pm 1^{\circ}$ temperature, 40-50\% humidity and $12 \mathrm{~h} \mathrm{light/dark} \mathrm{cycle.} \mathrm{Water} \mathrm{and}$ pelleted feed were provided ad libitum throughout the experimentation period. Acclimatization of the animals to the laboratory conditions was done $7 \mathrm{~d}$ prior to the initiation of the experiments. EGb was procured from Wilmar Schwabe, Germany. For oral administration, $\mathrm{EGb}$ and paroxetine were suspended in Tween 20 (10\%) and carboxy methyl cellulose (CMC, $1 \%)$, respectively and prepared freshly every day before administration. Animals treated with Tween 20 were considered as control.

\section{Grouping of animals:}

All rats were trained for spatial learning using Morris water maze ${ }^{[16]}$ and were randomly grouped for quinpirole-induced compulsive checking into 6 groups $(\mathrm{n}=6)$. Group I, control received Tween $200.1 \mathrm{ml} / 100 \mathrm{mg}$; group II, negative control; group III $(50 \mathrm{mg} / \mathrm{kg})$, group IV (100 mg/kg), group V (200 mg/kg) rats were treated with EGb and group VI treated with paroxetine $1.8 \mathrm{mg} / \mathrm{kg} / \mathrm{po}$ and served as the positive control. All groups except the control group received quinpirole $0.5 \mathrm{mg} / \mathrm{kg} /$ po twice a week for $35 \mathrm{~d}, 1 \mathrm{~h}$ prior to the exposure to the open field on the last day of the treatment. EGb and paroxetine were administered for $35 \mathrm{~d}$. To explore the marble burying behaviour, mice were grouped $(\mathrm{n}=6)$ as group I, control; group II $(50 \mathrm{mg} / \mathrm{kg})$, group III $(100 \mathrm{mg} / \mathrm{kg})$, group IV $(200 \mathrm{mg} / \mathrm{kg})$ were treated with $\mathrm{EGb}$ and group $\mathrm{V}$ mice were treated with paroxetine $1.8 \mathrm{mg} / \mathrm{kg} /$ po and served as positive control, all the treatments were done for $28 \mathrm{~d}$.

\section{Quinpirole-induced compulsive checking in rats:}

Rats were placed individually on a flat and large wooden open field $(1 \times 1 \mathrm{~m})$ consisting of 4 objects that differ in shape and colour and are fixed equidistantly at the corners. On the last day of the treatment, various behavioural parameters such as frequency and duration of stops, number of visits to other objects on successive return to each object and ritualistic behaviour were analysed single blinded (observer is unaware of the treatment) for a period of $55 \mathrm{~min}^{[17,18]}$ in a sound proof facility with glass partition. The open field was thoroughly deodorised after each observation.

\section{Effect on memory:}

The effect on memory was evaluated based on the retention of the learned task i.e. time taken for the identification of the hidden platform in the Morris water maze apparatus ${ }^{[16]}$.

\section{Marble burying behaviour of mice:}

Effect on marble burying behaviour was determined by placing mice individually in a cage with adequate bedding material for burying marbles. Five marbles of similar colour and dimensions were scattered over the bedding material and the mice were left undisturbed for $10 \mathrm{~min}$. The number of marbles buried at the end of 10 min was calculated after $1,14,28 \mathrm{~d}$ of treatment for all the groups ${ }^{[14]}$.

\section{Estimation of rat brain monoamine levels:}

After the study on retention of memory, rats were sacrificed by cervical dislocation and the brains were isolated quickly. Anaesthesia is avoided to eliminate the chance of alteration of neurotransmitters ${ }^{[19,20]}$. The brains were rapidly removed and the neurotransmitters 
levels of dopamine and 5-hydroxytryptamine were measured in the whole brain using fluorimetry based on the method by Kari et al. ${ }^{[21]}$.

\section{Statistical analysis:}

Behavioural parameters, frequency of stops and duration of stops were categorized as more and less and are compared using Bland-Altman analysis to determine the percent difference and bias for various objects (more $=$ sum of scores attained for two objects where more frequency of stops and duration of time spent was observed, less $=$ sum of scores attained at two objects where less frequency of stops and duration of time spent was observed). Non-parametric spearman correlation test was used to compare the number of visits to other objects on successive return to each object with that object of least number of visits. The effect on water maze test, brain monoamine levels and marble burying behaviour were analysed using one way ANOVA followed by Dunnet's ' $t$ ' test. A value of $p<0.05$ was considered statistically significant.

\section{RESULTS AND DISCUSSION}

Excessive stimulation of $\mathrm{OFC}$ and $\mathrm{ACC}$ resulting in generation of repetitive messages to basal ganglia and loss of error detection abilities are the two widely discussed pathological mechanisms of $\mathrm{OCD}^{[6]}$. The former's ability to explain various symptoms of OCD made it to be readily acceptable. The present study also supports this view, as quinpirole induced increase in dopaminergic activity has led to the increase in frequency of stops at specific objects on the open field in negative control groups, whereas rats of control group had rarely shown any such discrimination/ bias. The bias (difference in total number of stops between two objects with more frequency and that with less frequency, expressed as bias \pm SD) observed with Bland-Altman analysis was reported in Table 1, a bias of $27.6 \pm 14.9$ was observed with control group. Quinpirole-treated negative control group had shown a marked discrimination in the frequency of stops at different locales (bias of 116.9 \pm 11.1 ) was observed in quinpirole-treated group, indicating the development of obsessions for the objects. EGb at a dose of 50, 100 and $200 \mathrm{mg} / \mathrm{kg}$ had shown a marked decrease in the bias, $41.8 \pm 14.1,24.4 \pm 14.5$ and $20.4 \pm 42.1$, respectively when compared with that of negative control and no significant difference was observed between the treatments of EGb at 100, $200 \mathrm{mg} / \mathrm{kg}$ and paroxetine $26.5 \pm 11.8$.
Obsessions (likeliness) developed towards two objects in rats treated with quinpirole not only increased the frequency of stops for specific objects but also increased the duration of stopping at those objects, the results were tabulated in Table 2. A bias of $181.91 \pm 18.51$ was observed with negative control group, which was more than that observed with control group, i.e., $36.2 \pm 37.4$. Administration of EGb 50, 100 and $200 \mathrm{mg} / \mathrm{kg}$ had shown a marked reduction in the bias to $73.9 \pm 34.8$, $57.9 \pm 18.6$ and $37.1 \pm 36.2$, respectively, when compared with negative control. EGb-treatment at 100 and $200 \mathrm{mg} / \mathrm{kg}$ did not show any significant difference when compared with that of paroxetine-treated groups $58.07 \pm 47.81$.

Fig. 1 shows the performance on open field in which, number of visits to other objects on successive return to that object (marked as A, B, C and D) was observed, Spearman correlation test had shown that quinpirole treatment induced obsessions and had markedly reduced the number of visits to other objects on successive return to that object at two locales (object A-0.78, $\mathrm{B}-1, \mathrm{C}-3.67$ and $\mathrm{D}-4.23$ ) and no such difference was observed in control rats (object A-2.83, B-3.16, C-3.5 and D-3.33) indicating development of obsessions

TABLE 1: EFFECT OF EGb ON FREQUENCY OF STOPS AT DIFFERENT OBJECTS

\begin{tabular}{lcccc}
\hline \multirow{2}{*}{ Groups } & \multicolumn{2}{c}{ Frequency of stops } & Lverage & Bias \pm SD \\
\cline { 2 - 5 } & More & Less & & \\
\hline I & $19.67 \pm 1.55$ & $15 \pm 1.4$ & 17.3 & $27.56 \pm 14.92$ \\
II & $12 \pm 1.9$ & $3.3 \pm 0.71$ & 7.6 & $116.9 \pm 11.09$ \\
III & $16 \pm 2.4$ & $6.6 \pm 1.7$ & 11.3 & $41.8 \pm 14.1$ \\
IV & $15.3 \pm 1.7$ & $12.3 \pm 2.1$ & 13.8 & $24.4 \pm 14.5$ \\
V & $14.2 \pm 2.3$ & $10.8 \pm 0.7$ & 12.5 & $20.4 \pm 42.1$ \\
VI & $14.3 \pm 1.6$ & $11.2 \pm 0.6$ & 12.6 & $26.54 \pm 11.8$ \\
\hline
\end{tabular}

More and less denotes average of two objects where rats have shown more or less frequency of stops, respectively; SD is standard deviation of bias calculated using Bland-Altman analysis

TABLE 2: EFFECT OF EGb ON DURATION OF STOPS AT DIFFERENT OBJECTS

\begin{tabular}{lcccc}
\hline \multirow{2}{*}{ Groups } & \multicolumn{2}{c}{ Duration of stops } & \multirow{2}{*}{ Average } & Bias \pm SD \\
\cline { 2 - 5 } & More & Less & & \\
\hline I & $29.8 \pm 3.2$ & $21.5 \pm 4.3$ & 25.67 & $36.23 \pm 37.41$ \\
II & $41.49 \pm 6.3$ & $1.63 \pm 0.61$ & 21.78 & $181.91 \pm 18.51$ \\
III & $26.5 \pm 6.1$ & $12.5 \pm 3.1$ & 19.2 & $73.9 \pm 34.8$ \\
IV & $26.1 \pm 3.7$ & $14.6 \pm 4.2$ & 20.1 & $57.9 \pm 18.6$ \\
V & $19.6 \pm 1.7$ & $13.2 \pm 1.5$ & 16.4 & $37.1 \pm 36.2$ \\
VI & $25.5 \pm 3.78$ & $13.1 \pm 1.32$ & 19.25 & $58.07 \pm 47.81$ \\
\hline
\end{tabular}

More and less denotes average of two objects where rats have shown more or less duration of stopping, respectively; SD is standard deviation of bias was calculated using Bland-Altman analysis 


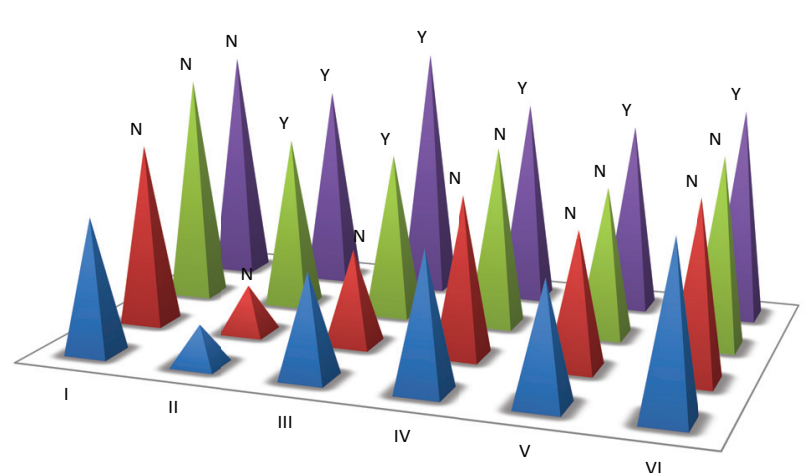

Fig. 1: Effect of EGb on open field performance

Number of visits to other objects on successive return to each object, A ( $\square)$, B ( $\square), C(\square)$, and D ( $\square)$. N and Y indicate nonsignificant and significant differences, respectively, obtained by non parametric spearman correlation test $(n=6)$ of number of visits on successive return to an object ( $B, C$ and $D)$ with that of the object (A) where less number of visits on successive return are shown, value represents average of total number of visits

towards those two objects. EGb at $50 \mathrm{mg} / \mathrm{kg}$ (object A-1.48, B-1.87, C-3.37 and D-3.83) did not show any significant decrease when compared with negative control, EGb $100 \mathrm{mg} / \mathrm{kg}$ (object A-2.8, B-3.3, C-3.83 and $\mathrm{D}-4.23$ ) and $200 \mathrm{mg} / \mathrm{kg}$ (object A-2.5, B-2.83, C-3.16 and D-4) had increased the number of visits to other objects when compared with that of quinpirole group, and the observed effects are similar to that of paroxetine-treated group (object A-3.5, B-3.66, C-4 and $\mathrm{D}-4.5)$. Involvement of serotonin in the etiology of OCD can be implied with the observed changes in the behavioural parameters. i.e. development of obsessions. The use of selective serotonin reuptake inhibitors (SSRI's) in the treatment of OCD further supported the same. Whereas, appearance of ritualistic behaviours at objects where rats have developed obsessions indicated that compulsions were developed to overcome the obsessions. EGb and paroxetine had also reduced the ritualistic behaviours, thus substantiating its efficacy in the treatment of OCD

EGb has been reported to improve learning ${ }^{[12]}$ and memory in Alzheimer's disease ${ }^{[22,23]}$. In the effect on memory as shown in fig. 2, no such retrieval of learned task (reaching the escape platform) was observed with quinpirole treatment as the time taken to identify the hidden platform increased to about $67.4 \pm 11.6 \mathrm{~s}$, which is significantly greater than that observed with control (23.2 \pm 5$)$, treatment with EGb 50, 100 and $200 \mathrm{mg} / \mathrm{kg}$ had shown a retention of memory, but was significant only with 100 and $200 \mathrm{mg} / \mathrm{kg}$ i.e. $34.9 \pm 5.8,30.4 \pm 3.5$, respectively and a significant effect was observed only with EGb $200 \mathrm{mg} / \mathrm{kg}$ when compared with paroxetine treatment.
SSRI's used in $\mathrm{OCD}^{[24]}$ are reported to attenuate the overactivity of the $\mathrm{OFC}$ by increasing $5-\mathrm{HT}_{2 \mathrm{~A}}$ and $5-\mathrm{HT}_{2 \mathrm{C}}$ receptor stimulation ${ }^{[25]}$. Involvement of norepinephrine, dopamine and high glutamate activity $^{[26]}$ in the pathogenesis of OCD are reported in many of the recent studies surpassing the studies that elucidate the role of serotonin alone in the neurobiology of $\mathrm{OCD}^{[27]}$. The following changes observed in the monoamine levels of whole brain as shown in fig. 3 substantiates this, a significant increase in the DA levels was observed in negative control group when compared to control. Rats treated with EGb 100 and $200 \mathrm{mg} / \mathrm{kg}$ had shown a significant decrease in DA levels at $772.6 \pm 14.8$ and $711.5 \pm 32.6 \mathrm{ng} / \mathrm{g}$, respectively and a significant increase in the 5-HT levels was observed only at 100 and $200 \mathrm{mg} / \mathrm{kg}, 577 \pm 23.5$ and $612 \pm 41.3 \mathrm{ng} / \mathrm{g}(\mathrm{p}<0.01)$, when compared to group II (negative control). No significant changes in the levels of DA and 5-HT were observed with EGb at $50 \mathrm{mg} / \mathrm{kg}$. Similarly significant increase in the 5-HT and decrease in the DA levels were observed when compared to that of negative control. DA levels were not significantly altered with paroxetine treatment, whereas a significant increase in 5-HT was observed. A significant difference was observed in the serotonin levels of EGb $50 \mathrm{mg} / \mathrm{kg}$ treatment when compared to that of paroxetine treatment and no significant difference was observed between $\mathrm{EGb}$ treatment and paroxetine.

Overactivity of dopaminergic system has been reported to be involved in $\mathrm{OCD}^{[28]}$, as basal ganglia is innervated with dopaminergic fibres and its dysfunction is considered to be the primary cause of

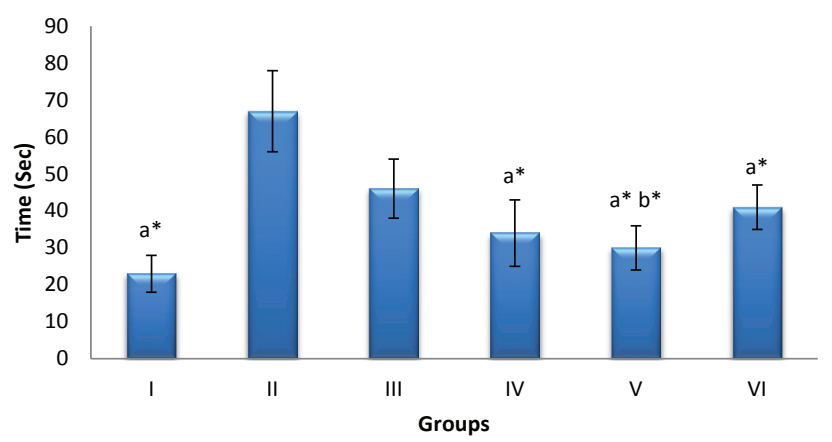

Fig. 2: Effect of EGb on retention of learned task

The delay in time to reach the escape platform from the starting point on the last day of treatment after exploration on open field, each column represents mean $\pm \operatorname{SEM}(n=6)$ of time taken by the rats to reach the escape platform from the starting point. Values of quinpirole-treated are compared with that of control group, a = values of control, EGb 50, 100 and $200 \mathrm{mg} / \mathrm{kg}$ and paroxetine compared with negative control, $b=$ values of EGb 50, 100 and $200 \mathrm{mg} / \mathrm{kg}$ compared with paroxetine-treated groups; *p $<0.05$ 


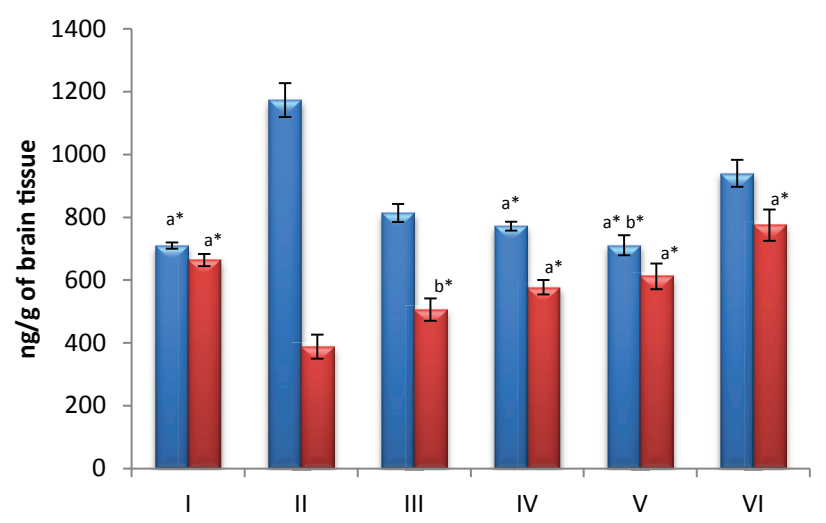

Fig. 3: Effect of EGb on whole brain dopamine and serotonin levels

Dopamine ( $\square$ ) and serotonin ( $\square)$; each column represents the mean and SEM $(n=6)$ of dopamine and serotonin levels $(\mathrm{ng} / \mathrm{g}$ of wet tissue). Values of quinpirole treatment are compared with control, a = values of EGb 50,100 and $200 \mathrm{mg} / \mathrm{kg}$ and paroxetine compared with negative control, $b=$ values of $\mathbf{E G b} 50,100$ and $200 \mathrm{mg} / \mathrm{kg}$ compared with paroxetine-treated groups; * $\mathbf{p}<0.05$

OCD. Malfunction of caudate nucleus in OCD prevents the, "error" signal from the OFC to the thalamus thus affecting the prevention of recurrence of the signal. So, the hyperactive thalamus creates a loop of worry signals that are never-ending between the thalamus and $\mathrm{OFC}^{[29]}$. Hence, in an attempt to relieve the observed apprehension due to repeated signalling, OFC responds by increasing anxiety or developing compulsive behaviours. Abnormality in the concentration of dopamine in amygdala and hippocampus might be the cause of memory disturbances in $\mathrm{OCD}^{[30]}$, as these are the structures that are actively involved in the consolidation of emotional and recent memory, respectively ${ }^{[28]}$, their innervation with dopaminergic fibres $^{[31,32]}$ further confirms its involvement in the memory disturbances observed with OCD.

The ritualistic behaviours, cleaning the snout with forepaws, repeated grooming with hind paws, was observed in quinpirole (negative control) rats at the objects where rats have developed obsessions and these compulsive behaviours were not observed in control group. Treatment with EGb and paroxetine had markedly reduced the severity of these behaviours. The interaction between the dopaminergic and serotonergic systems in the mid-brain regions i.e. substantia nigra and ventral tegmentum with dopaminergic neurons being targets for serotonin cells ${ }^{[28]}$ explains the involvement of 5-HT and DA in OCD. Activation of $5 \mathrm{HT}_{1 \mathrm{~A}}$ (auto receptor) inhibits DA release in the dorsal striatum and enhances dopamine release in nucleus accumbens ${ }^{[33]}$. This explains the possible mechanism of the effect of
SSRI's in the treatment of DA agonist induced OCD, as quinpirole is agonist to $\mathrm{D}_{2}$ and $\mathrm{D}_{3}$ receptors in the striatum $^{[17]}$, which in turn increases the dopamine levels. The increase in the serotonin concentration with $\mathrm{EGb}$, its role on $5 \mathrm{HT}_{1 \mathrm{~A}}$-auto-receptors, which inhibit dopamine release and studies on sertraline, that it decreases the extracellular dopamine in the striatum, further supports the observation ${ }^{[34]}$. Decrease in dopamine levels was observed in the present study, contributes to the protective effect of EGb and paroxetine in OCD.

The protective effect of EGb is reiterated by the study on the marble burying behaviour of mice. Burying of noxious or harmless material is the natural compulsive behaviour of the mice and the reduction in this behaviour is taken as an index of protection against compulsions in OCD, a multiple day study was chosen since, Hollander et al. ${ }^{[35]}$ reported that anxiolytic drugs like diazepam reduced compulsions initially but lost the protective effect on repeated administration. Whereas, drugs which operate through serotonergic mechanisms are protective against compulsive behaviour only on repeated administration, this is once again substantiated in the present study as single administration of EGb did not show any protective effect against compulsive behaviour. The results observed on single administration support this further, since SSRI's are reported to exhibit antiOCD effect only after repeated administration ${ }^{[36]}$.

Administration of drugs for $14 \mathrm{~d}$ have shown a further reduction in the number of marbles buried and a significant reduction was observed at both the dose levels of EGb 100, $200 \mathrm{mg} / \mathrm{kg}$ respectively when compared to that of control. Whereas, treatment for $28 \mathrm{~d}$ also had shown similar significance on the compulsive behaviour (marble burying), suggesting that repeated administration did not show any tolerance against the activity of these drugs and the protective effect is comparable to that of paroxetine, no significant decrease was observed with EGb $50 \mathrm{mg} / \mathrm{kg}$, results were summarized in Table 3. This protective effect could be due to the observed changes in the dopamine levels, as the strongest support for the role of DA in mediating OCD symptoms comes from the nonresponsiveness of approximately $40 \%$ of OCD patients to SSRI's and the relationship of symptoms of OCD with other disorders of abnormal DA in basal ganglia (Von economo's, encephalitis, Tourett's syndrome and sydenham's chorea) suggests the involvement of other 
TABLE 3: EFFECT OF EGb ON NUMBER OF MARBLES BURIED BY MICE

\begin{tabular}{lccc}
\hline \multirow{2}{*}{ Groups } & \multicolumn{3}{c}{ Duration of treatment (days) } \\
\cline { 2 - 4 } & 1 & 14 & 28 \\
\hline I & $4.3 \pm 0.3$ & $4 \pm 0.3$ & $4.2 \pm 0.3$ \\
II & $3.9 \pm 0.4^{\text {a ns }}$ & $3.1 \pm 0.3^{\text {a nsb ns }}$ & $2.8 \pm 0.2^{\text {a nsb }}$ \\
III & $4.1 \pm 0.3^{\text {a ns }}$ & $2.8 \pm 0.7^{a^{*} b^{*}}$ & $2.5 \pm 0.2^{\mathrm{a}^{*} \mathrm{~b}^{*}}$ \\
IV & $4.2 \pm 0.2^{\text {a ns }}$ & $2.4 \pm 0.3^{\mathrm{a}^{*} \mathrm{~b}^{*}}$ & $2.1 \pm 0.5^{\mathrm{a}^{*} \mathrm{~b}^{*}}$ \\
V & $3.8 \pm 0.5^{\text {a ns }}$ & $2.3 \pm 0.2^{\mathrm{a}^{*} \mathrm{~b}^{*}}$ & $2 \pm 0.4^{\mathrm{a}^{*} \mathrm{~b}^{*}}$ \\
\hline
\end{tabular}

Data represents mean \pm SEM of the no. of marbles buried (out of 5 ) in $10 \mathrm{~min}, \mathrm{a}=$ values of EGb 50, 100 and $200 \mathrm{mg} / \mathrm{kg}$ and paroxetine compared with control at respective days, $b=$ values of day 14 and 28 compared with that of day $1 .{ }^{*} p<0.05$, ns $=$ non-significant

neurotransmitters in the pathophysiology of OCD apart from serotonin ${ }^{[37]}$ i.e. dopamine.

OCD, involving abnormal processing of signals by ACC, OFC and basal ganglia are treated with antidepressants ${ }^{[38]}$, though they are incompletely effective in providing adequate therapeutic effect and are also involved in many adverse effects this study had made it evident that EGb exerts protective effect against OCD and its associated memory disturbances, and the underlying mechanism is accentuation of serotonin levels and decrease in dopamine levels (mediated through $5 \mathrm{HT}_{1 \mathrm{~A}}$-auto-receptors stimulation). The existing treatment includes prolonged use of antidepressants, which lead to many side effects such as dyskinesia, nervousness, anorexia, loss of libido and insomnia ${ }^{[39]}$. Hence, EGb could be an effective alternative, which could also reduce the side effects involved in the OCD treatment and its comorbidities. However, further studies such as, monoamine reuptake, inhibition of monoamine oxidase, sensitization and enhancement of receptor binding or neuroendocrine modulation that validate and substantiate the authenticity of these results are necessary to investigate the role of EGb to make it an effective alternative in the treatment of OCD and will reinstate the role of EGb on other pathological processes involved in OCD.

\section{REFERENCES}

1. Eisen JL, Mancebo MA, Pinto A, Coles ME, Pagano ME, Stout $\mathrm{R}$, et al. Impact of obsessive-compulsive disorder on quality of life. Compr Psychiatry 2006;47:270-75.

2. Hou SY, Yen CF, Huang MF, Wang PW, Yeh YC. Quality of life and its correlates in patients with obsessive-compulsive disorder. Kaohsiung J Med Sci 2010;26:397-407.

3. American Psychiatric Association: Diagnostic and Statistical Manual of Mental Disorders. Washington, DC: American Psychiatric Association; 2000.

4. Rotge JY, Guehl D, Dilharreguy B, Cuny E, Tignol J, Bioulac $\mathrm{B}$, et al. Provocation of obsessive-compulsive symptoms: a quantitative voxel-based meta-analysis of functional neuroimaging studies. J Psychiatry Neurosci 2008;33(5):405-
12.

5. Swinson RP, Antony MM, Rachman S, Richter MA: Obsessive-Compulsive Disorder - Theory, Research and Treatment. New York, NY: The Guilford Press; 1998.

6. Gladding B. Neurobiology of obsessive-compulsive disorder. Los Angeles, CA: Westwood Institute for Anxiety Disorders; 1999.

7. Karadag F, Oguzhanoglu N, Ozdel O, Atesci FC, Amuk T. Memory function in patients with obsessive-compulsive disorder and the problem of confidence in their memories: a clinical study. Croat Med J 2005;46:282-7.

8. Van den Hout M, Kindt M. Repeated checking causes memory distrust. Behav Res Ther 2003;41:301-16.

9. Park LT, Jefferson JW, Greist JH. Obsessive-compulsive disorder. Treatment options. CNS Drugs 1997;7:187-202.

10. Insel TR, Mueller EA, Alterman I, Linnoila M, Murphy DL. Obsessive-compulsive disorder and serotonin: is there a connection. Biol Psychiatry 1985;20(11):1174-88.

11. Bystritsky A. Current pharmacological treatments for obsessive-compulsive disorder. Essent Psychopharmacol 2004;5:251-72.

12. Kim KW, Lee DY. Obsessive-compulsive disorder associated with a left orbitofrontal infarct. J Neuropsychiatry Clin Neurosci 2002;14(1):88-9.

13. Pittenger $\mathrm{C}$, Bloch $\mathrm{MH}$, Williams K. Glutamate abnormalities in obsessive-compulsive disorder: neurobiology, pathophysiology, and treatment. Pharmacol Ther 2011;132(3):314-32.

14. Westenberg HG, Fineberg NA, Denys D. Neurobiology of obsessive-compulsive disorder: Serotonin and beyond. CNS Spectr 2007;12:14-27.

15. Hollander E, Stein DJ. Obsessive-compulsive DisorderDiagnosis, Etiology, Treatment. New York, NY: Marcel Dekker; 1997.

16. Saki K, Bahmani M, Rafieian-Kopaei M. The effect of most important medicinal plants on two important psychiatric disorders (anxiety and depression)-a review. Asian Pac J Trop Med 2014;7S1:34-42.

17. Anonymous. EGb: Ginkgo biloba extract, Ginkor. Drugs R D 2003;4:188-93.

18. Woelk H, Arnoldt KH, Kieser M, Hoerr R. Ginkgo biloba special extract $\mathrm{EGb}{ }^{\circledR}$ in generalized anxiety disorder and adjustment disorder with anxious mood: A randomized, double-blind, placebo-controlled trial. J Psychiatr Res 2007;41:472-80.

19. Ramassamy C, Longpre F, Christen Y. Ginkgo biloba extract (EGb) in Alzheimer's disease: is there any evidence? Curr Alzheimer Res 2007;4(3):253-62.

20. Shi C, Liu J, Wu F, Yew DT. Ginkgo biloba extract in Alzheimer's disease: from action mechanisms to medical practice. Int J Mol Sci 2010;11(1):107-23.

21. Kari HP, Davidson PP, Herbert HH, Kochhar MH. Effects of ketamine on brain monoamine levels in rats. Res Commun Chem Path Pharmacol 1978;20(3):475-88.

22. Tripathi KD. Drugs Used in Mental Illness: Antidepressant and Antianxiety Drugs. New Delhi, India: Jaypee Medical Publishers; 2008.

23. Hanish Singh JC, Muralidharan P, Narsimha Reddy Y, Sathesh Kumar S, Alagarsamy V. Anti-amnesic effects of Evolvulus alsinoides linn. In amyloid $\beta$ (25-35) induced neurodegeneration in mice. Pharmacol Online 2009;1:70-80. 
24. Szechtman H, Sulis W, Eilam D. Quinpirole induces compulsive checking behaviour in rats: A potential animal model of obsessive-compulsive disorder (OCD). Behav Neurosci 1998;112:1475-85.

25. Szechtman H, Eckert MJ, Wai ST, Boersma JT, Bonura CA, McClelland JZ, et al. Compulsive checking behaviour of quinpirole-sensitized rats as an animal model of ObsessiveCompulsive Disorder (OCD): form and control. BMC Neurosci 2001;2:4-10.

26. Jithendra C, Murthy TE, Upadyay L. Protective role of curcumin in maximal electroshock induced seizures, memory impairment and neurotransmitters in rat brain. J Pre Clin Clin Res 2008;2:35-9.

27. Ravindran R, Rathinasamy SD, Samson J, Senthilvelan M. Noise-stress-induced brain neurotransmitter changes and the effect of Ocimum sanctum (Linn) treatment in albino rats. J Phamacol Sci 2005;98:354-60.

28. Chimakurthy J, Murthy TE. Effect of curcumin on quinpirole induced compulsive checking: An approach to determine the predictive and construct validity of the model. N Am J Med Sci 2010;2(2):81-5.

29. Banin RM, de Andrade IS, Cerutti SM, Oyama LM, Telles MM, Ribeiro EB. Ginkgo biloba Extract (GbE) Stimulates the Hypothalamic Serotonergic System and Attenuates Obesity in Ovariectomized Rats. Front Pharmacol 2017;8:605-11.

30. Mohamed NE, El-Moneim AE. Ginkgo biloba extract alleviates oxidative stress and some neurotransmitters changes induced by aluminum chloride in rats. Nutrition 2017;35:93-9.
31. Kulkarni SK. Hand book of experimental pharmacology. 3rd ed. New Delhi: Vallabh Prakashan; 2004.

32. Morris R. Development of a water-maze procedure for studying spatial learning in the rat. J Neurosci Methods 1984;11(1):47-60.

33. Huey ED, Zahn R, Krueger F, Moll J, Kapogiannis D, Wassermann EM, et al. A psychological and neuroanatomical model of obsessive-compulsive disorder. J Neuropsychiatry Clin Neurosci 2008;20(4):390-408.

34. Tallis F. The neuropsychology of obsessive-compulsive disorder: a review and consideration of clinical implications. Br J Clin Psychol 1997;36:3-20.

35. Hollander E, Allen A, Steiner M, Wheadon DE, Oakes R, Burnham DB. Acute and long-term treatment and prevention of relapse of obsessive-compulsive disorder with paroxetine. J Clin Psych 2003;64:1113-21.

36. Dahlstroem A, Fuxe K. Evidence for the existence of monoamine containing neurons in the central nervous system. Acta Physiol Scand Suppl 1964;Suppl 232: 1-55.

37. Foote SL, Bloom FE, Aston JG. Pharmacology and physiology of central noradrenergic systems. In: Bloom FE, Kupfer DJ. editors. Psychopharmacology: The Fourth Generation of Progress. New York, NY: Raven Press; 1994.

38. Zohar J, Judge R. Paroxetine versus clomipramine in the treatment of obsessive-compulsive disorder. OCD Paroxetine Study Investigators. Br J Psychiatry 1996;169(4):468-74.

39. McManamy J. Dopamine - serotonin's secret weapon. McMan's Depression and Bipolar Web. Connecticut; McManweb: 2008. 